\title{
Difunctionalization of alkenes with iodine and tert-butyl hydroperoxide (TBHP) at room temperature for the synthesis of 1-(tert-butylperoxy)-2-iodoethanes
}

\author{
Hao Wang ${ }^{1}$, Cui Chen², Weibing Liu* ${ }^{* 2}$ and Zhibo Zhü ${ }^{* 1}$

\section{Letter} \\ Address: \\ ${ }^{1}$ Integrated Hospital of Traditional Chinese Medicine, Southern \\ Medical University, Guangzhou, 510315, P. R. China. Fax: +86- 20- \\ 6164 8538; Tel: +86- 20 -62789464 and ${ }^{2}$ College of Chemical \\ Engineering, Guangdong University of Petrochemical Technology, 2 \\ Guandu Road, Maoming 525000, P. R. China. Fax: \\ +86-668-2923575; Tel: +86-668-2923956

\section{Email:} \\ Weibing Liu* - Iwb409@gdupt.edu.cn.; Zhibo Zhu* - \\ zhuzb676@smu.edu.cn \\ * Corresponding author \\ Keywords: \\ difunctionalization of alkenesiodine; iodination-peroxidation reaction; \\ TBHP \\ Beilstein J. Org. Chem. 2017, 13, 2023-2027. \\ doi:10.3762/bjoc. 13.200 \\ Received: 01 July 2017 \\ Accepted: 08 September 2017 \\ Published: 28 September 2017 \\ Associate Editor: L. Vaccaro \\ (C) 2017 Wang et al.; licensee Beilstein-Institut. \\ License and terms: see end of document.
}

\begin{abstract}
We developed a direct vicinal difunctionalization of alkenes with iodine and TBHP at room temperature. This iodination and peroxidation in a one-pot synthesis produces 1-(tert-butylperoxy)-2-iodoethanes, which are inaccessible through conventional synthetic methods. This method generates multiple radical intermediates in situ and has excellent regioselectivity, a broad substrate scope and mild conditions. The iodine and peroxide groups of 1-(tert-butylperoxy)-2-iodoethanes have several potential applications and allow further chemical modifications, enabling the preparation of synthetically valuable molecules.
\end{abstract}

\section{Introduction}

Alkenes have attracted considerable interest in recent years as abundant, simple chemical feedstocks and organic molecules, owing to their potential for extensive application in organic syntheses. Approaches for the efficient, regio- and chemoselective difunctionalization of alkenes have been developed that are attractive for rapidly building complex difunctionalized molecules from simple starting materials in a single operation [1-6] Traditional studies have mainly focused on transition-metal-cat- alyzed direct vicinal difunctionalization of alkenes by installing two substituents across the $\mathrm{C}=\mathrm{C}$ double bond to form two new bonds or two new functional groups [7-9], such as dioxygenation [10,11], dihydroxylation [10,12], bisperoxidation [13], oxyamidation [14], aminohydroxylation [15], oxyphosphorylation [16], deamination [17] and carbonylation-peroxidation [18]. Several very recent reports have pertained to metal-free catalysts for difunctionalization of alkenes such as UV light 
$[19,20]$, hypervalent iodine reagents [21,22], acids [23], organoammonium iodides [24] and iodine [25]. These catalysts are often employed in combination with a peroxide and generally produce an organoperoxide. Organic peroxides are important and useful compounds because of their unique chemical and biological properties [26,27]. Organoperoxides have wide applications in the field of organic synthesis, as radical initiators, oxidants that replace transition metal oxidants, and key reactive intermediates in diverse organic synthesis reactions [28-30], as well as in medicinal chemistry and pharmacology as medicines and therapeutic drugs [31,32]. Although many methods have been developed to synthesize peroxides [33-35], they have a tendency to decompose because the peroxy (-OO-) bond is easily cleaved and peroxides are highly sensitivity to reducing agents. New and general methods to construct peroxides are still highly desirable and valuable, and highly regioselective and efficient syntheses of peroxides with structural control are still difficult to achieve. Herein, we report a metal-free iodination-peroxidation reaction for the direct vicinal difunctionalization of alkenes with iodine and tert-butyl hydroperoxide (TBHP) at room temperature to synthesize 1-(tert-butylperoxy)-2-iodoethanes that are inaccessible via conventional synthetic routes (Scheme 1). To the best of our knowledge, $\beta$-iodoalkyl tert-butyl peroxides are important organic compounds due to their unique structural features, which make them available to serve as starting materials for a wide range of organic oxidations to access other oxygenated products [36].

$$
\begin{aligned}
& \mathrm{R}_{\mathrm{R}^{1}}^{\mathrm{R}} \underset{\mathrm{R}}{\stackrel{\mathrm{I}_{2} / \mathrm{TBHP}}{\text { toluene }}} \\
& \mathrm{R}=\mathrm{Ar} \text {, alkyl } \\
& \mathrm{R}^{1}=\mathrm{H}, \mathrm{Ar}, \text { alkyl } \\
& \mathrm{R}^{2}=\text { alkyl, } \mathrm{H}
\end{aligned}
$$

Scheme 1: Synthesis of 1-(tert-butylperoxy)-2-iodoethanes.

\section{Results and Discussion}

A pilot reaction setup comprised of styrene (1a, $208 \mathrm{mg}$, $2.0 \mathrm{mmol}$ ) in the presence of $\mathrm{I}_{2}$ (1.0 equiv), TBHP (2.0 equiv), and $\mathrm{CH}_{3} \mathrm{CN}(2.0 \mathrm{~mL})$ was investigated to determine the optimal reaction conditions. Stirring this mixture at room temperature for $12 \mathrm{~h}$ afforded the desired product (2-iodo-1-(tertbutylperoxy)ethyl)benzene (2a) in $45 \%$ yield, which was further improved to $59 \%$ by extending the reaction time to $24 \mathrm{~h}$ (Table 1, entries 1-3). The reaction was quite sensitive to the solvent medium (Table 1, entries 2, 4-8). Among the various solvents examined, toluene proved to be the most suitable sol- vent, furnishing $\mathbf{2 a}$ in $72 \%$ yield (Table 1, entry 8 ). Further screening studies were conducted by altering the amounts of $\mathrm{I}_{2}$ and TBHP to find the optimum reaction conditions. Notably, decreasing the amount of $\mathrm{I}_{2}$ to 0.5 equiv decreased the yield to $51 \%$ (Table 1, entry 9). An excess of 3.0 equiv of TBHP or more gave the highest product yields (Table 1, entries 8, 10 and 11).

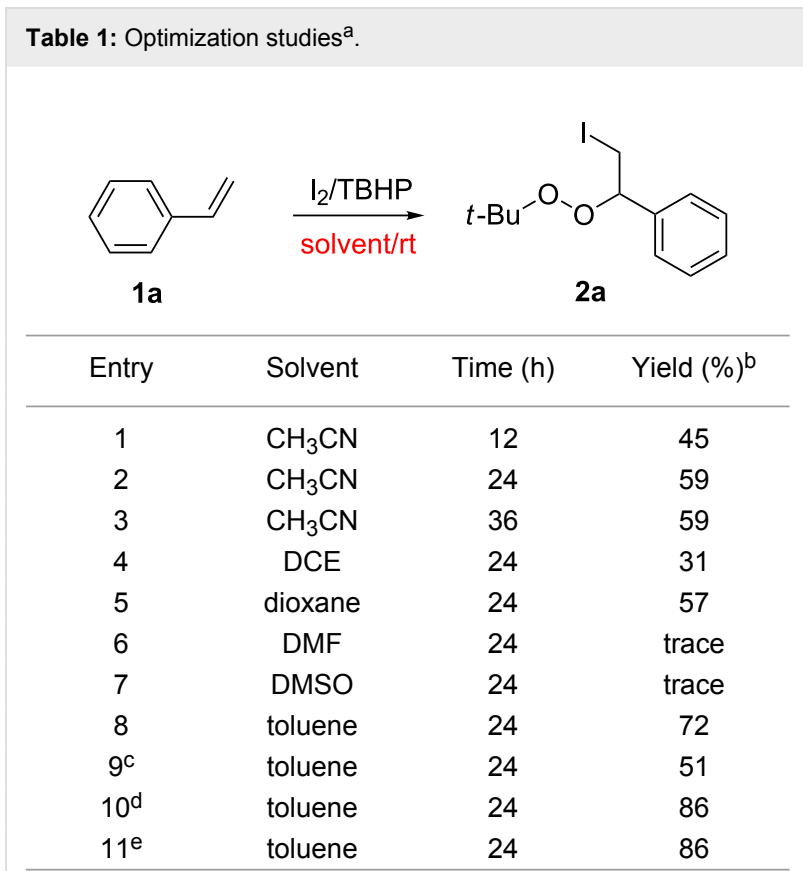

aUnless otherwise specified, all reactions were carried out on $1 \mathrm{a}$ $0.5 \mathrm{mmol}$ scale, iodine 1.0 equiv, tert-butyl hydroperoxide (TBHP) 2.0 equiv, solvent $2.0 \mathrm{~mL}$; byield calculated by $\mathrm{GC}$; $\mathrm{Cl}_{2}: 0.5$ equiv; dTBHP: 3.0 equiv; ${ }^{\text {TTBHP: }} 4.0$ equiv.

A variety of substituted alkenes were then tested under the optimal reaction conditions identified above. Styrenes $(\mathrm{R}=\mathrm{Ar}$; $\left.\mathrm{R}^{1}=\mathrm{R}^{2}=\mathrm{H}\right) \mathbf{1} \mathbf{a}-\mathbf{i}$ bearing functional groups with different electronic properties on the phenyl ring were all tolerated and did not substantially alter the reaction efficiency (Scheme 2). Substrates bearing electron-withdrawing substituents (i.e., fluoroand chloro-) performed slightly more effectively in this reaction than those bearing electron-donating substituents (i.e., methyl-, phenyl-, chloromethyl-, tert-butyl- and methoxy-), and afforded the corresponding products in relatively high yields.

Notably, the yield of this iodination-peroxidation reaction appeared to be unaffected by the position of the same substituent on the phenyl ring. For example, all pairs of 1-methyl-4vinylbenzene and 1,4-dimethyl-2-vinylbenzene, 1-chloro-4vinylbenzene and 1-chloro-3-vinylbenzene, 1-fluoro-4-vinylbenzene and 1-fluoro-3-vinylbenzene gave almost identical yields of the corresponding products. In addition, the inclusion 


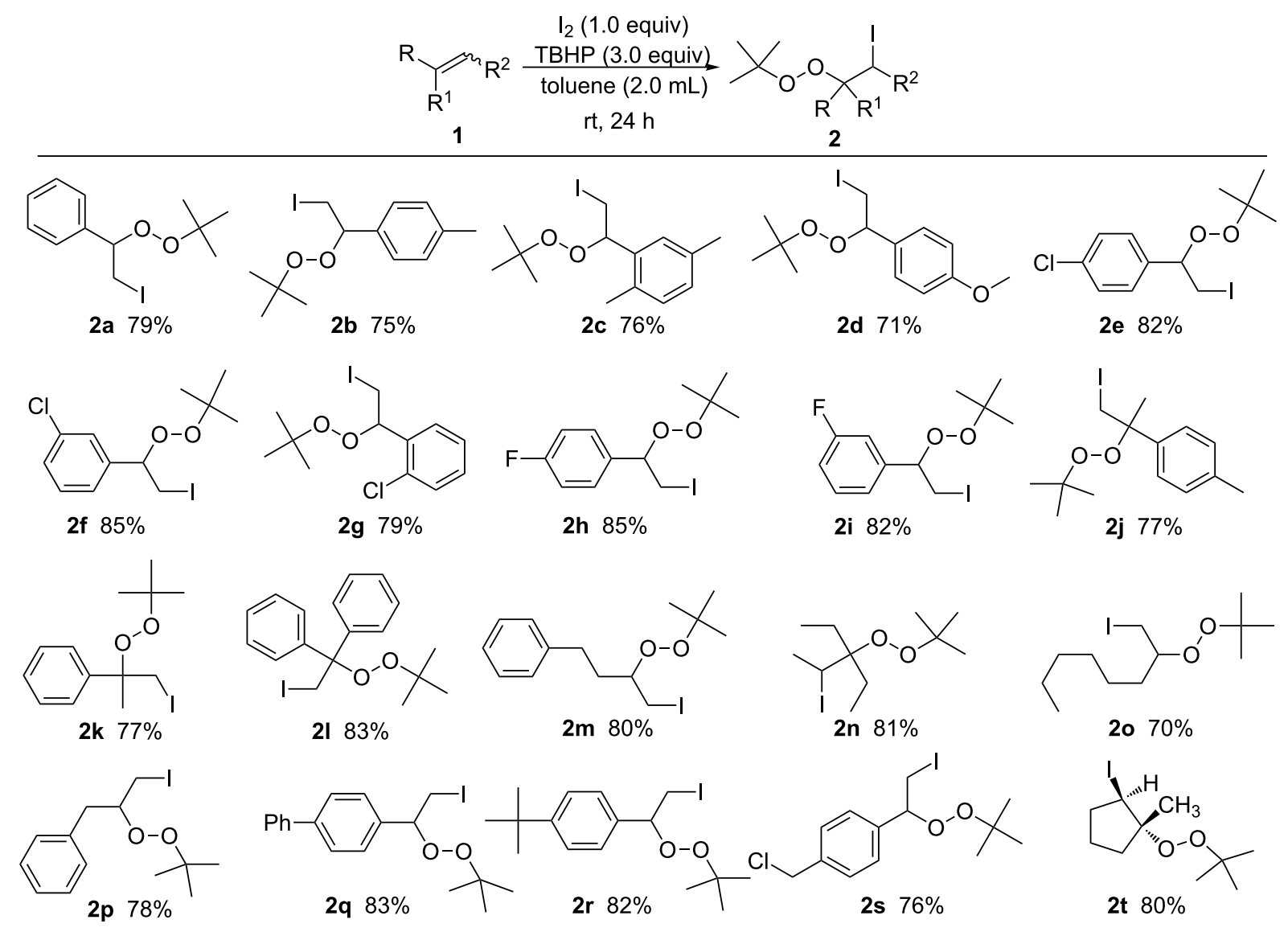

Scheme 2: Direct vicinal difunctionalization of alkenes. All reactions were carried out on a $2.0 \mathrm{mmol}$ scale using toluene $(2.0 \mathrm{~mL})$ as the solvent and all the listed yields are isolated yields.

of different $\mathrm{R}^{1}$ and $\mathrm{R}^{2}$ groups on styrenes, such as 1,1-disubstituted/1,2-disubstituted/1,1,2-trisubstituted alkenes (1-(prop-1en-2-yl)benzene, 1-methyl-4-(prop-1-en-2-yl)benzene and 1,1diphenylethene), had no discernible impact on the outcome of this iodination-peroxidation reaction. The scope of this reaction was further extended to a series of chain alkenes, such as 1-(but-3-enyl)benzene), 1-allylbenzene, oct-1-ene and 3-ethylpent-2-ene, which all reacted as anticipated to give the corresponding products in moderate to excellent isolated yields (70-81\%). It is noteworthy that monosubstituted and 1,1-disubstituted terminal alkenes $\mathbf{1 j} \mathbf{j}-\mathbf{l}$, as well 1,2,2-trisubstituted internal alkenes 3-ethylpent-2-ene (1n) and 1-methylcyclopent1-ene (1t) under the developed conditions, all result the anticipated products with excellent yields. Especially, according to the detection of NMR and NOE analysis, the substrate 1 -methylcyclopent-1-ene (1t) affords $(1 R, 2 R)$-1-(tertbutylperoxy)-2-iodo-1-methylcyclopentane (2t) as the only product. And even more exciting this reaction was easily scaled up to $10 \mathrm{mmol}$ with no obvious loss in product formation efficiency.
We investigated the addition of the radical inhibitor TEMPO (2,2,6,6-tetramethylpiperididine- $N$-oxyl) to gain an insight into the mechanism of this reaction. The reaction was completely inhibited in the presence of TEMPO, suggesting that a radical pathway may be operating in this reaction. Therefore, we propose a possible mechanism for the reaction in Scheme 3, exemplified by the formation of $\mathbf{2 a}$, based on the aforementioned results and previous literature [36-39]. The process commences with the formation of $t$-BuOI and HOI from the initial reaction of TBHP with $\mathrm{I}_{2}$ [40]. The subsequent iodination reaction could proceed via a homolytic attack involving $t$-BuOI and HOI to generate intermediate 3 , tert-butoxyl radicals and hydroxyl radicals[41]. In the presence of TBHP, a fast reaction between tert-butoxyl radicals and TBHP take place, leading to the formation of tert-butylperoxyl radicals and tertiary butanol $[41,42]$. Subsequently, the radical 3 can be further oxidized into cation 4 with $\mathrm{I}_{2}[24,43,44]$. The iodide ion is then reoxidized with TBHP to regenerate $\mathrm{I}_{2}$ and tert-butoxyl radicals $[24,45]$. Finally, cation 4 can be attacked by TBHP to give the final product $\mathbf{2 a}$. 


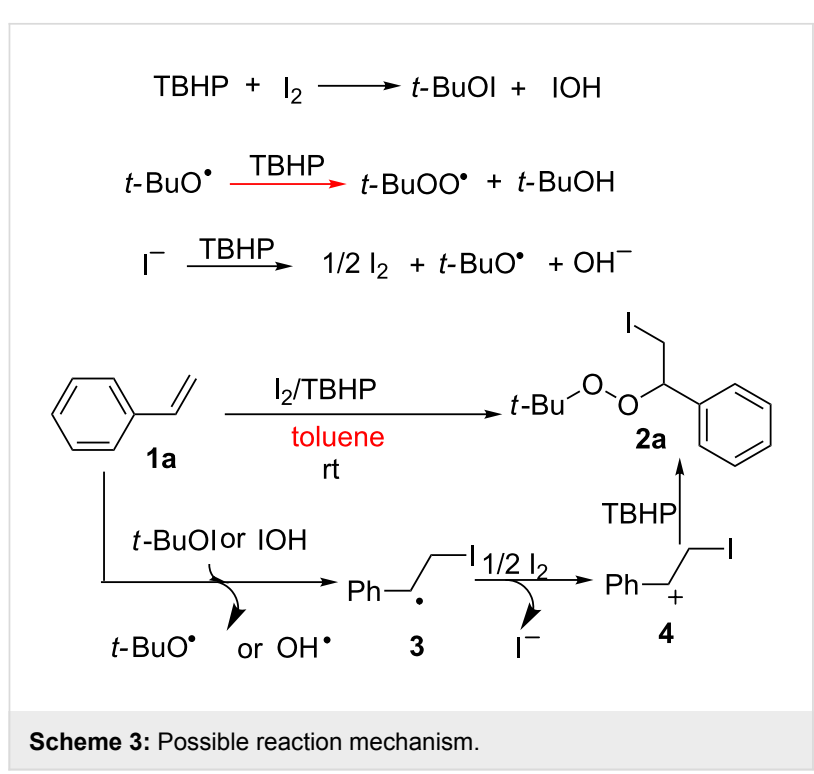

\section{Conclusion}

In summary, we have established a metal-free process at room temperature for the direct vicinal difunctionalization of alkenes with iodine and TBHP to synthesize 1-(tert-butylperoxy)-2iodoethanes. This procedure is a simple and high-yielding method with excellent regioselectivity for iodination and peroxidation of the $\mathrm{C}=\mathrm{C}$ double bond of alkenes and shows good functional group compatibility. Furthermore, the mild reaction conditions of this methodology and the ease of further modification of the iodine and peroxide groups in 1-(tert-butylperoxy)-2-iodoethanes indicate that this procedure has good potential for application in the fields of organic synthesis, medicinal chemistry and pharmacology. Further work toward expanding this protocol and investigations into the difunctionalization of alkenes with other electrophiles is currently underway in our laboratory, and the results will be reported in due course.

\section{Supporting Information}

\section{Supporting Information File 1}

Full experimental details and copies of NMR spectral data. [http://www.beilstein-journals.org/bjoc/content/ supplementary/1860-5397-13-200-S1.pdf]

\section{Acknowledgements}

This work was supported by the National Natural Science Foundation of China (81373263), Guangzhou Science and Technology Project (201604020009), Guangdong Provincial Department of Science and Technology (No.916014) and the Department of Education of Guangdong Province (No.916021) for financial support.

\section{References}

1. Bloodworth, A. J.; Bowyer, K. J.; Mitchell, J. C. J. Org. Chem. 1986, 51, 1790. doi:10.1021/jo00360a027

2. Wang, A.; Jiang, H.; Chen, H. J. Am. Chem. Soc. 2009, 131, 3846. doi:10.1021/ja900213d

3. Ashikari, Y.; Shimizu, A.; Nokami, T.; Yoshida, J.-i. J. Am. Chem. Soc. 2013, 135, 16070. doi:10.1021/ja4092648

4. Guo, J.-Y.; Wu, R.-X.; Jin, J.-K.; Tian, S.-K. Org. Lett. 2016, 18, 3850. doi:10.1021/acs.orglett.6b01862

5. Cyr, P.; Côté-Raiche, A.; Bronner, S. M. Org. Lett. 2016, 18, 6448. doi:10.1021/acs.orglett.6b03345

6. Liao, J.; Fan, L.; Guo, W.; Zhang, Z.; Li, J.; Zhu, C.; Ren, Y.; Wu, W.; Jiang, H. Org. Lett. 2017, 19, 1008. doi:10.1021/acs.orglett.6b03865

7. Manna, M. K.; Hossian, A.; Jana, R. Org. Lett. 2015, 17, 672. doi:10.1021/ol5036968

8. Yin, G.; Mu, X.; Liu, G. Acc. Chem. Res. 2016, 49, 2413 doi:10.1021/acs.accounts.6b00328

9. Hu, F.; Nareddy, P.; Lalancette, R.; Jordan, F.; Szostak, M. Org. Lett. 2017, 19, 2386. doi:10.1021/acs.orglett.7b00913

10. Bataille, C. J. R.; Donohoe, T. J. Chem. Soc. Rev. 2011, 40, 114. doi:10.1039/B923880H

11. Xue, Q.; Xie, J.; Xu, P.; Hu, K.; Cheng, Y.; Zhu, C. ACS Catal. 2013, 3, 1365. doi:10.1021/cs400250m

12. Kolb, H. C.; VanNieuwenhze, M. S.; Sharpless, K. B. Chem. Rev. 1994, 94, 2483. doi:10.1021/cr00032a009

13. Terent'ev, A. O.; Sharipov, M. Y.; Krylov, I. B.; Gaidarenko, D. V.; Nikishin, G. I. Org. Biomol. Chem. 2015, 13, 1439. doi:10.1039/C4OB01823K

14. Liskin, D. V.; Sibbald, P. A.; Rosewall, C. F.; Michael, F. E. J. Org. Chem. 2010, 75, 6294. doi:10.1021/j0101171g

15. Beccalli, E. M.; Broggini, G.; Martinelli, M.; Sottocornola, S. Chem. Rev. 2007, 107, 5318. doi:10.1021/cr068006f

16. Zhou, S.-F.; Li, D.-P.; Liu, K.; Zou, J.-P.; Asekun, O. T. J. Org. Chem 2015, 80, 1214. doi:10.1021/jo5023298

17. Du, H.; Zhao, B.; Shi, Y. J. Am. Chem. Soc. 2007, 129, 762. doi:10.1021/ja0680562

18. Liu, W.; Li, Y.; Liu, K.; Li, Z. J. Am. Chem. Soc. 2011, 133, 10756. doi:10.1021/ja204226n

19. Courant, T.; Masson, G. J. Org. Chem. 2016, 81, 6945. doi:10.1021/acs.joc.6b01058

20. Zheng, L.; Huang, H.; Yang, C.; Xia, W. Org. Lett. 2015, 17, 1034. doi:10.1021/acs.orglett.5b00144

21. Xu, D.; Sun, W.-W.; Xie, Y.; Liu, J.-K.; Liu, B.; Zhou, Y.; Wu, B. J. Org. Chem. 2016, 81, 11081. doi:10.1021/acs.joc.6b02078

22. Huang, L.; Zheng, S.-C.; Tan, B.; Liu, X.-Y. Org. Lett. 2015, 17, 1589. doi:10.1021/acs.orglett.5b00479

23. Schweitzer-Chaput, B.; Kurtén, T.; Klussmann, M. Angew. Chem., Int. Ed. 2015, 54, 11848. doi:10.1002/anie.201505648

24. Mondal, B.; Sahoo, S. C.; Pan, S. C. Eur. J. Org. Chem. 2015, 3135. doi:10.1002/ejoc.201500233

25. Cui, H.; Liu, X.; Wei, W.; Yang, D.; He, C.; Zhang, T.; Wang, H. J. Org. Chem. 2016, 81, 2252. doi:10.1021/acs.joc.5b02579

26. Dragan, A.; Kubczyk, T. M.; Rowley, J. H.; Sproules, S.; Tomkinson, N. C. O. Org. Lett. 2015, 17, 2618. doi:10.1021/acs.orglett.5b00953

27. Alamillo-Ferrer, C.; Davidson, S. C.; Rawling, M. J.; Theodoulou, N. H.; Campbell, M.; Humphreys, P. G.; Kennedy, A. R.; Tomkinson, N. C. O. Org. Lett. 2015, 17, 5132. doi:10.1021/acs.orglett.5b02674 
28. Arzumanyan, A. V.; Terent'ev, A. O.; Novikov, R. A.; Lakhtin, V. G.; Grigoriev, M. S.; Nikishin, G. I. Organometallics 2016, 35, 1667. doi:10.1021/acs.organomet.6b00129

29. Tan, F.-L.; Song, R.-J.; Hu, M.; Li, J.-H. Org. Lett. 2016, 18, 3198. doi:10.1021/acs.orglett.6b01419

30. Jana, A.; Grela, K. Org. Lett. 2017, 19, 520. doi:10.1021/acs.orglett.6b03688

31. Wu, Y. Acc. Chem. Res. 2002, 35, 255. doi:10.1021/ar000080b

32. Graham, I. A.; Besser, K.; Blumer, S.; Branigan, C. A.; Czechowski, T.; Elias, L.; Guterman, I.; Harvey, D.; Isaac, P. G.; Khan, A. M.; Larson, T. R.; Li, Y.; Pawson, T.; Penfield, T.; Rae, A. M.; Rathbone, D. A.; Reid, S.; Ross, J.; Smallwood, M. F.; Segura, V.; Townsend, T.; Vyas, D.; Winzer, T.; Bowles, D. Science 2010, 327, 328. doi:10.1126/science.1182612

33. Shi, E.; Liu, J.; Liu, C.; Shao, Y.; Wang, H.; Lv, Y.; Ji, M.; Bao, X.; Wan, X. J. Org. Chem. 2016, 81, 5878. doi:10.1021/acs.joc.6b00575

34. Zong, Z.; Lu, S.; Wang, W.; Li, Z. Tetrahedron Lett. 2015, 56, 6719. doi:10.1016/j.tetlet.2015.10.052

35. Jiang, J.; Liu, J.; Yang, L.; Shao, Y.; Cheng, J.; Bao, X.; Wan, X. Chem. Commun. 2015, 51, 14728. doi:10.1039/C5CC05183E

36. Jereb, M.; Zupan, M.; Stavber, S. Green Chem. 2005, 7, 100. doi:10.1039/b407592g

37. Barluenga, J.; Marco-Arias, M.; González-Bobes, F.; Ballesteros, A.; González, J. M. Chem. - Eur. J. 2004, 10, 1677. doi:10.1002/chem.200305582

38. Schulz, M.; Rieche, A.; Kirschke, K. Chem. Ber. 1967, 100, 370. doi:10.1002/cber.19671000141

39. Terentév, A. O.; Krylov, I. B.; Borisov, D. A.; Nikishin, G. I. Synthesis 2007, 2979. doi:10.1055/s-2007-990776

40.Sun, K.; Lv, Y.; Wang, J.; Sun, J.; Liu, L.; Jia, M.; Liu, X.; Li, Z.; Wang, X. Org. Lett. 2015, 17, 4408. doi:10.1021/acs.orglett.5b01857

41. Schweitzer-Chaput, B.; Demaerel, J.; Engler, H.; Klussmann, M. Angew. Chem., Int. Ed. 2014, 53, 8737. doi:10.1002/anie.201401062

42. Paul, H.; Small, R. D., Jr.; Scaiano, J. C. J. Am. Chem. Soc. 1978, 100 , 4520. doi:10.1021/ja00482a033

43. Feng, J.; Liang, S.; Chen, S.-Y.; Zhang, J.; Fu, S.-S.; Yu, X.-Q. Adv. Synth. Catal. 2012, 354, 1287. doi:10.1002/adsc.201100920

44. Xue, Q.; Xie, J.; Li, H.; Cheng, Y.; Zhu, C. Chem. Commun. 2013, 49, 3700. doi:10.1039/c3cc41558a

45. Reddi, R. N.; Prasad, P. K.; Sudalai, A. Org. Lett. 2014, 16, 5674. doi:10.1021/ol5027393

\section{License and Terms}

This is an Open Access article under the terms of the Creative Commons Attribution License

(http://creativecommons.org/licenses/by/4.0), which permits unrestricted use, distribution, and reproduction in any medium, provided the original work is properly cited.

The license is subject to the Beilstein Journal of Organic Chemistry terms and conditions:

(http://www.beilstein-journals.org/bjoc)

The definitive version of this article is the electronic one which can be found at:

doi:10.3762/bjoc. 13.200 